\title{
Avaliação ultrassonográfica da involução das estruturas umbilicais extra e intracavitárias em bezerros sadios da raça Nelore concebidos naturalmente e produtos de fertilização in vitro ${ }^{1}$
}

\author{
Tiago Torrecillas Sturion², Marco Aurélio Torrecillas Sturion², Domingos José Sturion² \\ e Júlio Augusto Naylor Lisboa ${ }^{3 *}$
}

\begin{abstract}
Sturion T.T., Sturion M.A.T., Sturion D.J. \& Lisboa J.A.N. 2013. [Ultrasound evaluation of extra- and intra-abdominal umbilical structures involution in healthy Nelore calves products of natural conception or in vitro fertilization.] Avaliação ultrassonográfica da involução das estruturas umbilicais extra e intracavitárias em bezerros sadios da raça Nelore concebidos naturalmente e produtos de fertilização in vitro. Pesquisa Veterinária Brasileira 33(8):1021-1032. Departamento de Clínicas Veterinárias, Centro de Ciências Agrárias, Universidade Estadual de Londrina, Campus Universitário, Cx. Postal 6001, Londrina, PR 86051-990, Brazil. E-mail: janlisboa@uel.br

THIS study was carried out to characterize the involution of the umbilical cord structures in healthy Nelore calves during their first 35 days of life, and to compare this process in calves conceived by natural methods or by in vitro fertilization (IVF). Forty calves were separated in two groups $(n=20)$ according to their conception method (natural or IVF) and each group consisted of ten male and ten female calves. The ultrasound (7.5 MHz micro convex transducer) was used to examine all the remaining structures of the umbilical cord that make the external navel and the abdominal structures (umbilical vein, left umbilical artery and allantoic duct), and their diameters were measured in distinct locations. The examinations were performed between 24 and 36 hours of life and at 7, 14, 21, 28 and 35 days of age. The effects of sex, age and method of conception were tested by repeated measures ANOVA. The ultrasound examination was suitable for evaluation of extra- and intra-abdominal umbilical structures and characterization of its involutive physiological process. Both veins were visualized in the external umbilicus up to 14 days of life and set of structures in process of atrophy were seen after this age. In the abdomen, the artery and the vein could be examined up to 35 days of age, and the allantoic duct only during the first week of life. These structures showed a regular and consistent hyperechoic wall and a homogeneous anechoic lumen. The diameter of all studied structures decreased throughout the first month of life $(p<0.05)$ without any sex effect ( $p>0.05$ ). The umbilical vessels and the allantoic duct were slightly wider (diameter 1-3 mm larger) in calves conceived by IVF. Differently from the highest values previously demonstrated for Bos taurus calves, we can disclose that in healthy newborn Nelore calves the thickness of the structures which make the external navel should not exceed $2 \mathrm{~cm}$, the diameter of the umbilical vein and artery can reach $1 \mathrm{~cm}$ and the diameter of the allantoic duct is close to $0.5 \mathrm{~cm}$.
\end{abstract}

INDEX TERMS: Navel, umbilical vein, umbilical artery, urachus, newborn calves, Zebu, ultrasound.

\footnotetext{
${ }^{1}$ Recebido em 10 de agosto de 2012.

Aceito para publicação em 25 de março de 2013

Dissertação de Mestrado do primeiro autor pelo Programa de Pós-Graduação em Ciência Animal da Universidade Estadual de Londrina (UEL).

${ }^{2}$ Docente do Curso de Medicina Veterinária das Faculdades Integradas de Ourinhos (FIO), Rodovia BR 153 Km 339, Bairro Água do Cateto, Ourinhos, SP 19909-100, Brasil.

${ }^{3}$ Departamento de Clínicas Veterinárias, CCA, UEL, Campus Universitário, Cx. Postal 6001, Londrina, PR 86051-9901, Brasil. *Autor para correspondência: janlisboa@uel.br
}

RESUMO.- Esse trabalho foi desenvolvido com o objetivo de caracterizar a involução das estruturas umbilicais em bezerros sadios da raça Nelore ao longo dos primeiros 35 dias de vida, e de comparar esse processo em bezerros concebidos por métodos naturais ou por fertilização in vitro (FIV). Quarenta bezerros foram distribuídos em dois grupos $(n=20)$ de acordo com o método de concepção (natural ou FIV) e cada grupo foi composto por dez machos e dez fêmeas. A ultrassonografia (transdutor microconvexo de 
7,5 MHz) foi empregada para examinar o conjunto das estruturas remanescentes do cordão umbilical que compõem o umbigo externo e as estruturas abdominais (veia umbilical, artéria umbilical esquerda e ducto alantóide), mensurando-se os seus diâmetros em locais definidos. Os exames foram realizados entre 24 e 36 horas de vida e aos 7, 14, 21,28 e 35 dias de idade. Testaram-se os efeitos do sexo, da idade e do método de concepção por meio da análise de variâncias de medidas repetidas. 0 exame ultrassonográfico provou-se adequado para a avaliação das estruturas umbilicais extra e intracavitárias permitindo a caracterização do processo fisiológico de involução das mesmas. No umbigo externo, as veias umbilicais foram observadas como imagem individualizada até os 14 dias de vida e um conjunto de estruturas em processo de atrofia era visualizado após essa idade. No abdômen, a veia e a artéria umbilicais foram visualizadas até os 35 dias de idade e o ducto alantóide somente durante a primeira semana de vida. Essas estruturas apresentaram-se com parede hiperecóica regular e contínua e lúmen homogeneamente anecóico. 0 diâmetro de todas as estruturas umbilicais estudadas se reduziu continuamente ao longo do primeiro mês de vida $(\mathrm{p}<0,05)$, sem efeito do sexo $(\mathrm{p}>0,05)$. Comparados aos bezerros concebidos por métodos naturais, os produtos de FIV nasceram com os vasos umbilicais e o ducto alantóide um pouco mais calibrosos (diâmetros 1 a $3 \mathrm{~mm}$ maiores). Distintamente dos valores mais elevados estabelecidos em estudos prévios para os bezerros de raças européias, pode-se admitir, por fim, que nos bezerros recém-nascidos sadios da raça Nelore a espessura das estruturas que compõem o umbigo externo não deve ultrapassar $2 \mathrm{~cm}$, o diâmetro da veia e da artéria umbilicais pode chegar a $1 \mathrm{~cm}$ e o do ducto alantóide é próximo a $0,5 \mathrm{~cm}$.

TERMOS DE INDEXAÇÃO: Umbigo, veia umbilical, artéria umbilical, úraco, bezerros neonatos, zebuínos, ultrassom.

\section{INTRODUÇÃO}

O cordão umbilical, presente no embrião desde os 30 dias após a concepção (Assis Neto et al. 2010), é formado por cinco estruturas principais: duas veias umbilicais, duas artérias umbilicais e o ducto alantóide. As veias se fusionam próximo ao anel umbilical e sua principal função é o transporte do sangue oxigenado da placenta em direção ao fígado do feto (Noden \& Lahunta 2001, Dyce et al. 2004, Nuss 2007). As duas artérias umbilicais possuem origem nas ilíacas internas, passam lateralmente à bexiga, uma de cada lado, em direção à placenta e conduzem o sangue fetal não oxigenado (Dyce et al. 2004, Nuss 2007). 0 ducto alantóide se continua a partir da bexiga do feto e possui a função de conduzir a urina produzida pelo feto até o saco alantóide (Noden \& Lahunta, 2001, Nuss 2007). Após o nascimento, a veia, as artérias e o ducto alantóide não possuem função e se atrofiam. Essas estruturas podem ser a sede de doenças nos bezerros neonatos.

As afecções umbilicais podem ser agrupadas, de acordo com a sua causa, em: não infecciosas, como as hérnias umbilicais e o úraco patente ou persistente; e infecciosas que, conforme a sua localização, são reagrupadas em extra e intracavitárias. Os processos extrabdominais são denominados onfalites, e os intrabominais recebem as seguintes denominações de acordo com a estrutura acometida: onfaloflebite, onfaloarterite, onfalouraquite e suas combinações (Figueirêdo 1999).

O diagnóstico das afecções umbilicais se baseia no histórico, e nos resultados dos exames físico (inspeção e palpação) e hematológico (Trent \& Smith 1984, Geishauser \& Grunder 1992). As onfalites são, de forma geral, facilmente diagnosticadas pelos métodos semiológicos rotineiros, mas os processos que afetam as estruturas umbilicais intracavitárias requerem métodos diagnósticos mais específicos. Radiografias abdominais, fistulografia e urografia excretora são exemplos de métodos complementares de diagnóstico (Bouckaert \& de Moor 1965, Diefenderfer \& Brightling 1983). Por sua praticidade e aplicação no campo, o exame ultrassonográfico deve ser considerado atualmente o método mais valioso para revelar os problemas nas estruturas umbilicais intrabdominais (Baxter et al. 1989, Lischer \& Steiner 1994, Edwards III \& Fubini 1995, Staller et al. 1995, 0’Brien \& Forrest 1996).

A ultrassonografia foi utilizada para avaliar a involução ou atrofia das estruturas umbilicais abdominais ao longo das primeiras semanas de vida em bezerros sadios (Lischer \& Steiner 1993, Watson et al. 1994). As mensurações dos diâmetros da veia e da artéria umbilicais foram estabelecidas em diferentes idades, caracterizando o processo natural de atrofia e os valores obtidos possuem grande importância porque são utilizados como referência para a interpretação e o diagnóstico de anormalidades nessas estruturas. Em ambos os estudos examinaram-se bezerros de raças taurinas. Até o momento, são desconhecidos esses valores de referência em bezerros zebuínos.

Rodrigues et al. (2010) apontaram maior ocorrência de enfermidades umbilicais em bezerros Nelore concebidos artificialmente, pela técnica de produção in vitro de embriões (PIVE), mas a causa para isso ainda não está devidamente esclarecida. Como evidenciado na rotina prática, esses bezerros podem nascer com os vasos umbilicais mais calibrosos, os quais se atrofiam mais lentamente. No caso dos bezerros clonados já está bem caracterizado que nascem com tamanho e peso maiores, com vasos umbilicais de maior diâmetro e apresentam maior chance de desenvolverem doenças umbilicais (Garry et al. 1996, Batchelder et al. 2007, Miglino et al. 2007, Meirelles et al. 2010). A ocorrência da síndrome do bezerro grande (Large Offspring Syndrome) é comumente descrita em animais frutos de processos artificiais de fertilização e não somente nos bezerros clonados (Behboodi et al. 1995, Kruip \& den Daas 1997, Young et al. 1998, Jacobsen et al. 2000, Bertolini \& Anderson 2002, Farin et al. 2006, 2010). A maior susceptibilidade dos bezerros produtos de PIVE à doença umbilical é um assunto que merece ser melhor esclarecido.

0 presente estudo foi desenvolvido com o objetivo de avaliar, por ultrassonografia, o processo de involução das estruturas componentes do umbigo externo, da veia umbilical, da artéria umbilical e do ducto alantóide em bezerros saudáveis da raça Nelore entre o nascimento e os 35 dias de vida, e de comparar os animais frutos de concepção natural com os produtos de PIVE. 


\section{MATERIAL E MÉTODOS}

O projeto foi aprovado pelo Comitê de Ética e Experimentação Animal da Universidade Estadual de Londrina, registrado sob o número de protocolo CEEA/UEL 24/2009. 0 experimento foi realizado em uma propriedade rural localizada no município de Santo Antônio da Platina, PR $\left(23^{\circ} 14^{\prime} 37^{\prime \prime} S\right.$ de latitude e $50^{\circ} 00^{\prime} 22^{\prime \prime} \mathrm{W}$ de longitude e altitude de 533 metros acima do nível do mar), na qual são criados bovinos da raça Nelore, sendo a produção e venda de matrizes e de reprodutores, a principal exploração.

Foram incluídos no estudo 40 bezerros sadios da raça Nelore, acompanhados do nascimento até os 35 dias de vida. Os bezerros foram agrupados de acordo com o método de concepção do qual eram fruto: concepção natural (fertilização in vivo por monta natural ou inseminação artificial) e concepção artificial (produção in vitro de embriões - PIVE); totalizando 20 animais por grupo. Cada grupo foi constituído ainda por número igual de bezerros de cada sexo (10 machos e 10 fêmeas).

Os nascimentos ocorreram entre novembro de 2009 e setembro de 2010, independentemente do método de concepção, sem uma distribuição sazonal definida. Os bezerros produtos de PIVE eram filhos de nove touros distintos e de 12 vacas diferentes das quais se obtiveram oócitos por punção ovariana guiada por ultrassonografia. Os embriões obtidos por fertilização in vitro foram transferidos a fresco para as fêmeas receptoras previamente sincronizadas. As receptoras eram fêmeas $1 / 2$ sangue Nelore, frutos de cruzamentos com as raças Pardo Suíça, Simental ou Red Angus. Dentre as receptoras sete eram novilhas e as demais já haviam parido uma $(n=4)$, duas $(n=6)$ ou três vezes $(n=3)$. Os bezerros concebidos por métodos naturais (10 produtos de monta natural e 10 produtos de inseminação artificial) eram filhos de 11 touros diferentes. Dentre as mães duas eram novilhas e as demais já haviam parido uma $(n=8)$, duas $(n=4)$, três $(n=5)$ ou quatro vezes $(\mathrm{n}=1)$. Não foram incluídos gêmeos nesse estudo.

Os partos aconteciam em piquetes próprios para a observação mais intensiva da parturiente e não houve indução do parto em nenhuma das fêmeas do estudo. Após o parto os bezerros permaneciam em contato direto com as suas mães e realizavam a mamada natural do colostro. Todos os animais eram mantidos em regime de manejo extensivo em pastagens de Brachiaria brizantha ou de grama Estrela roxa (Cynodon nlemfuensis) com oferta permanente de água e de sal mineralizado comercial ${ }^{4}$ à vontade. Os bezerros e suas mães permaneceram sob vigilância regular (de três a quatro vezes por dia) durante todo o período de duração do experimento.

Para todos os bezerros nascidos na propriedade o mesmo manejo era adotado, independente do método de concepção. Após a primeira mamada do colostro ou, no máximo, até 8 horas de vida, realizava-se a antissepsia do umbigo com produto comercial contendo diclorvós, ácido pícrico, iodofórmio e fenol ${ }^{5}$, aplicando-o externamente e internamente no cordão umbilical remanescente exposto, uma única vez. Um mililitro de ivermectina $1 \%{ }^{6}$ era aplicado em dose única, por via subcutânea. Nenhum bezerro foi vacinado até os 35 dias de vida.

Os bezerros foram examinados em seis idades: entre 24 e 36 horas após o nascimento e aos sete, 14, 21, 28 e 35 dias de vida. Na anamnese eram registradas, em fichas individuais, as informações de cada bezerro desde o nascimento até a sua quinta semana de vida. Dentre as informações obtidas estavam hora de nascimento, peso ao nascimento, hora da primeira mamada, tipo de parto, dia da concepção e identificação da mãe (receptora e/ou progenitora) e do touro. Todas as ocorrências de alteração da saúde e tratamentos eram registradas.

Com utilização de fita métrica, foram mensurados, na primeira avaliação (24 a 36 horas de vida), os dados biométricos de altura da cernelha, circunferência torácica (posicionando a fita métrica imediatamente caudal ao olécrano) e comprimento da coluna vertebral (do ponto cranial do atlas até a primeira vértebra coccígea). Para realização desses procedimentos os bezerros eram contidos manualmente em estação.

O exame físico dos bezerros consistiu em avaliação das estruturas umbilicais extracavitárias por inspeção e por palpação, avaliando-se, subjetivamente, tamanho e consistência. As estruturas, em conjunto, foram mensuradas com auxílio de um paquímetro posicionado em dois locais distintos: dois centímetros acima da cicatriz umbilical e na posição mais elevada, imediatamente próxima ao anel umbilical na parede abdominal. Para a realização desses procedimentos e de todos os demais subsequentes os bezerros permaneceram contidos manualmente em decúbito lateral direito. Empregou-se o paquímetro convencional metálico com dupla haste de correr, sem mola.

As estruturas umbilicais intracavitárias eram avaliadas por palpação profunda abdominal empregando-se as duas mãos para a compressão necessária. A palpação da cavidade abdominal se iniciava a partir do anel umbilical em sentido cranial e dorsal em direção ao fígado, para avaliação da veia umbilical, e em sentido caudal em direção à bexiga, para avaliação das artérias umbilicais e do ducto alantóide. 0 exame permitia avaliar a espessura e a consistência dessas estruturas, caracterizando a situação fisiológica (consistência macia, indolor e, geralmente, dificuldade para identificar as estruturas individualizadas) ou a presença de processos patológicos (aumento de volume e alteração da consistência facilitando a indentificação das estrutras afetadas e presença de dor), conforme critérios já descritos (Geishauser \& Grunder 1992, Figueirêdo 1999).

No exame ultrassonográfico de cada animal e em cada idade eram identificadas e mensuradas as seguintes estruturas: veia umbilical, artéria umbilical esquerda e ducto alantóide (localizados internamente na cavidade abdominal) e estruturas remanescentes do cordão umbilical (localização extracavitária).

Devido ao alto valor comercial dos bezerros estudados e por motivos estéticos não foi possível realizar a tricotomia. Como alternativa para minimizar a interferência dos pêlos e garantir a qualidade da imagem, foram adotados os seguintes procedimentos: na parede abdominal direita aplicou-se álcool etílico $50^{\circ} \mathrm{GL}$, e aguardaram-se 10 minutos para ocorrer a penetração do mesmo. Decorrido este tempo, e com pêlos e pele ainda úmidos, o meio de contato para transmissão ultrassônica (diluído uma parte de gel para uma parte de água) era aplicado na mesma região com a finalidade de aumentar o acoplamento acústico do transdutor. 0 equipamento utilizado foi o aparelho de ultrassonografia veterinário, com transdutor bifrequencial micro convexo $5,0 / 7,5 \mathrm{MHz}^{7}$. A frequência de 7,5 MHz em modo B foi a empregada em todas as avaliações realizadas nesse estudo, independente da estrutura examinada. As imagens produzidas foram guardadas em foto de impressão (sonograma) e em formato digital com dimensão de $100 \mathrm{~mm} \times 100 \mathrm{~mm}$.

As estruturas intrabdominais avaliadas (artéria umbilical esquerda, veia umbilical e ducto alantóide) foram escaneadas em apenas um plano, o longitudinal. A veia umbilical foi acompanhada desde o anel umbilical até o fígado e o seu diâmetro foi medido

\footnotetext{
${ }^{4}$ Guabiphos 90 Cria ${ }^{\circledR}$; Guabi Ltda; Rua Magnólia 2405, Jardim das Bandeiras, Campinas, $\mathrm{SP}$.

${ }^{5}$ Umbicura ${ }^{\circledR}$, Pecuarista d'oeste de Araçatuba Ltda, Rua Brigadeiro Faria Lima 7827, Pq. Industrial, Araçatuba, SP.

${ }^{6}$ Ivomec Injetavel $囚$, Merial Saúde Animal Ltda, Avenida Carlos Grimaldi 1610, São Quirino, Campinas, SP.

${ }^{7}$ Aquila Pro Vet $®$, Esaote Europe B.V., Phillipweg 1, 6227 AJ Maastricht, Holanda.
} 
em quatro locais: a) imediatamente próximo ao anel umbilical; b) em um ponto intermediário entre o anel umbilical e o fígado; c) na chegada ao fígado e d) no interior do fígado (dentro do parênquima hepático imediatamente antes de ocorrer a sua bifurcação). Ao contrário do sentido adotado para o exame da veia umbilical, e em razão da maior facilidade de reconhecimento da bexiga que é uma janela acústica na região abdominal caudal, a artéria esquerda e o ducto alantoide foram sempre avaliados a partir da bexiga em direção cranial ao anel umbilical. 0 diâmetro da artéria foi mensurado em três locais: a) lateralmente à bexiga; b) um centímetro à frente do pólo cranial da bexiga; e c) dois centímetros caudais ao anel umbilical. 0 diâmetro do ducto alantóide foi medido em quatro locais distintos: a) no pólo cranial da bexiga; b) um centímetro à frente do pólo cranial da bexiga; c) cinco centímetros à frente do pólo cranial da bexiga (posição intermediária entre a bexiga e o anel umbilical); e d) dois centímetros caudais ao anel umbilical (Fig.1).

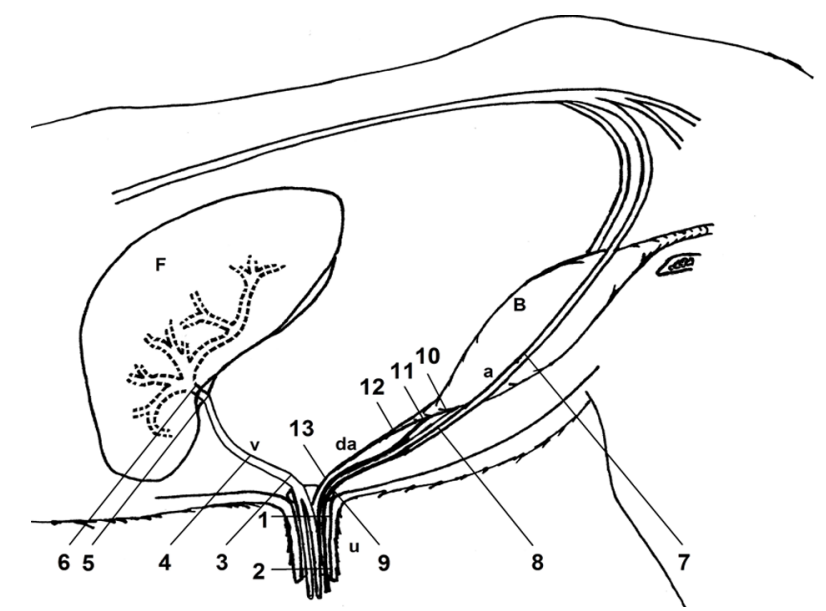

Fig.1. Locais onde foram realizadas as mensurações de espessura do conjunto das estruturas que compõem o umbigo externo (u; medidas 1 e 2) e do diâmetro na veia umbilical (v; medidas 3 a 6), na artéria umbilical esquerda (a; medidas 7 a 9) e no ducto alantóide (da; medidas 10 a 13). Órgãos para referência: fígado (F) e bexiga (B).

As estruturas extracavitárias remanescentes do cordão umbilical foram avaliadas em plano transversal e mensuradas, como um conjunto único, nos mesmos dois locais em que se realizou a medição por paquimetria: a) dois centímetros acima da cicatriz umbilical; e b) na posição mais elevada, imediatamente próximo ao anel umbilical na parede abdominal (Fig.1).

Amostras de sangue foram colhidas de cada bezerro em cada idade estudada por meio de punção da veia jugular externa com agulha 2,5x0,8 cm e tubo a vácuo contendo EDTA (etileno-diamino-tetra-ácido) a 10\% para a realização do hemograma e da dosagem de fibrinogênio plasmático. As amostras eram identificadas individualmente e transportadas em caixa isotérmica contendo gelo reciclável. Os exames hematológicos foram realizados segundo os métodos tradicionalmente empregados em hematologia (Coles 1986a, 1986b) com a contagem total de hemácias e de leucócitos realizada em câmara de Newbauer, a concentração de hemoglobina determinada pelo método da cianometahemoglobina, o volume globular determinado pelo método do microhematócrito, e as contagens diferenciais dos leucócitos realizadas em esfregaços sanguíneos corados pelo método de coloração panótico rápido ${ }^{8}$. A concentração plasmática da proteína total (PTP)

\footnotetext{
${ }^{8}$ Panótico Rápido LB®, Laborclin produtos para laboratórios Ltda, Rua Cassemiro de Abreu 521, Pinhais, PR.
}

foi determinada por refratometria e o fibrinogênio plasmático foi dosado empregando-se o método de precipitação pelo calor e a leitura refratométrica (Kaneko 1997).

Foram admitidos e mantidos no estudo somente os bezerros que se mantiveram saudáveis ao longo dos seus primeiros 35 dias de idade. Até mesmo os seis bezerros (quatro concebidos por PIVE e dois por meio natural) produtos de partos que necessitaram a intervenção, com tração manual com a força de um ou dois homens, apresentaram comportamento compatível com o de recém-nascidos que exibem boa vitalidade, e mamaram o colostro dentro das cinco primeiras horas de vida. Todos os bezerros originalmente admitidos no estudo que manifestaram alteração de saúde identificada, em qualquer das idades estudadas, pelo exame físico e/ou ultrassonográfico, foram excluídos.

Os resultados dos exames hematológicos e das dosagens de fibrinogênio foram utilizados como parâmetros objetivos indicadores de higidez. Os limites fisiológicos admitidos para o volume globular (30 a 45\%) e para os leucócitos totais (7.000 a 15.000/ $\mathrm{mm}^{3}$ ), assim como a relação dinâmica entre os neutrófilos e os linfócitos circulantes ao longo do primeiro mês de vida com a sua inversão a partir dos 14 dias de idade, tiveram como base os valores de referência estabelecidos por Biondo et al. (1998) e Fagliari et al. (1998) em bezerros da raça Nelore. Para a concentração de fibrinogênio plasmático admitiu-se o limite superior fisiológico de 700mg/dL, independente de faixa etária (Kaneko 1997).

Para o estudo das variáveis de mensurações das estruturas umbilicais, realizadas por meio de paquimetria e de ultrassonografia, a análise de variâncias de medidas repetidas bifatorial foi empregada inicialmente para testar os efeitos do sexo, da idade e a interação entre esses dois fatores, considerando, em separado, os bezerros frutos de cada um dos dois métodos de concepção (natural e PIVE). Por não haver efeito do sexo, o mesmo método estatístico foi empregado, subsequentemente, para testar os efeitos da idade, do método de concepção e a interação entre esses dois fatores. Quando a estatística F resultou significativa, empregou-se o teste de Tukey para a comparação entre médias, admitindo-se uma probabilidade de erro de $5 \%$. As variáveis de biometria dos bezerros na primeira idade agrupados de acordo com o método de concepção foram comparadas pelo teste t.

\section{RESULTADOS E DISCUSSÃO}

As avaliações do peso ao nascimento de bezerros frutos de diversos métodos de concepção foram objetivo de estudos comparando principalmente os métodos de concepção naturais (monta natural, inseminação artificial e transferência de embriões) e os artificiais (produção de embriões in vitro e clones). Em alguns destes estudos foi observado peso ao nascimento superior em animais concebidos por biotécnicas artificiais (Garry et al. 1996, Kruip \& den Daas 1997, Jacobsen et al. 2000, Batchelder et al. 2007, Meirelles et al. 2010).

No presente estudo, os bezerros concebidos naturalmente nasceram com peso e comprimento da coluna vertebral menores $(\mathrm{p}<0,05)$ do que os produtos de PIVE $(32,57 \pm 5,01 \mathrm{~kg}$ versus $36,90 \pm 5,71 \mathrm{~kg}$; e $75,0 \pm 4,95 \mathrm{~cm}$ versus $78,35 \pm 5,19 \mathrm{~cm})$. A altura da cernelha $(81,0 \pm 4,68 \mathrm{~cm}$ versus $83,4 \pm 5,69 \mathrm{~cm})$ e o perímetro torácico $(73,35 \pm 3,63 \mathrm{~cm}$ versus $75,45 \pm 3,51 \mathrm{~cm})$, ao contrário, não diferiram nos bezerros agrupados de acordo com o método de concepção. Esses valores são, de forma geral, compatíveis com os apontados em bezerros da raça Nelore concebidos por métodos naturais (Santos et al. 2005) e por PIVE (Gasparelli et al. 2009). 
Considerando os valores individuais, cinco bezerros produtos de PIVE nasceram com peso maior do que $40 \mathrm{~kg}$ (sendo $46 \mathrm{~kg}$ o peso máximo observado em dois animais) e nenhum bezerro concebido por método natural ultrapassou esse limite (sendo $40 \mathrm{~kg}$ o peso máximo observado em três neonatos). 0 maior peso observado nos produtos de PIVE reforça evidências anteriores em bezerros taurinos de diferentes raças (Hasler et al. 1995, Jacobsen et al. 2000, Numabe et al. 2000, Bertolini \& Anderson 2002), mas contradiz outras (Jacobsen et al. 2003, Rérat et al. 2005). Definitivamente, não caracteriza, nos animais estudados, a ocorrência da condição denominada de Síndrome do Recém-nascido Grande (Large Offspring Syndrome), a qual é relatada em bezerros concebidos por métodos artificias in vitro (Young et al. 1998, Farin et al. 2006, 2010). Gasparelli et al. (2009), acompanhando o nascimento de 122 bezerros Nelore produtos de PIVE, chegaram a observar dois bezerros nascidos com peso entre 50 e $59 \mathrm{~kg}$, e três com peso superior a $60 \mathrm{~kg}$.

Durante a avaliação do cordão umbilical remanescente nos bezerros entre 24 e 36 horas de vida, pôde-se observar que essa estrutura se apresentava úmida e flexível na maioria dos produtos de PIVE e menos flexível e mais ressecada na sua extremidade distal nos bezerros concebidos naturalmente. Com sete dias de idade o cordão umbilical remanescente já havia caído em quase todos os bezerros desse grupo (18/20) e a cicatrização da pele era completa aos 14 $(4 / 20)$ ou $21(16 / 20)$ dias. A maior parte dos produtos de PIVE ainda exibia o cordão ressecado ao final da primeira semana $(14 / 20)$ e a cicatrização da pele se completou aos $21(3 / 20)$ ou $28(17 / 20)$ dias. De acordo com os resultados de Hides \& Hannah (2005), sob condições fisiológicas, a queda do cordão umbilical remanescente mumificado ocorre entre cinco e oito dias de vida em bezerros leiteiros, e pode chegar até 10 dias nos zebuínos (Figueirêdo 1999). A cicatrização da pele se completa em três a quatro semanas (Nuss 2007).

Por se tratarem de bezerros sadios, durante a palpação do umbigo (estruturas umbilicais extracavitárias recobertas pela pele) nunca se observou presença de dor ou aumento da temperatura local, e as estruturas sempre mantiveram o formato cilíndrico. A consistência se modificou com o avançar da idade sem distinção aparente entre os dois grupos estudados, caracterizando o processo natural de involução e fibrosamento dessas estruturas, conforme descrito por Figueirêdo (1999) e por Nuss (2007). Após o nascimento, as estruturas eram flácidas, com consistência mole, sendo possível distinguir as veias umbilicais como unidades separadas. Aos 14 dias de vida as estruturas eram mais enrijecidas e a partir dos 21 ou 28 dias eram firmes e pouco flexíveis.

A involução do conjunto das estruturas umbilicais extracavitárias com o avançar da idade se caracteriza pela diminuição progressiva do seu calibre e foi avaliada objetivamente por meio de mensurações realizadas com paquimetria e com ultrassonografia (Quadro 1). Os valores médios obtidos por paquimetria foram naturalmente 1 a $2 \mathrm{~mm}$ maiores do que os obtidos pela ultrassonografia porque no primeiro método a espessura da pele é inevitavelmente incluída na mensuração. Nos dois grupos experimentais, a espessura do conjunto das estruturas umbilicais se reduziu gradativamente até os 35 dias de idade e o processo foi mais acelerado nas primeiras quatro semanas de vida. Em todos os momentos avaliados os bezerros de PIVE apresentaram estruturas umbilicais maiores $(\mathrm{p}<0,05)$ do que os bezerros de concepção natural. Não se constatou efeito do sexo em qualquer um dos métodos empregados para as mensurações ( $p>0,05)$.

Os valores médios obtidos por ultrassonografia podem ser comparados somente com os observados por Watson et al. (1994), os quais avaliaram as estruturas do umbigo em bezerros sadios da raça Holandesa entre 24 horas de vida e a terceira semana de idade, e apontaram espessura aproximadamente $1 \mathrm{~cm}$ maior do que a dos bezerros Nelore estudados. Isso pode caracterizar distinções morfológicas entre as raças. Os valores nos bezerros Nelores são mais parecidos com os relatados em potros, ao nascimento e ao final da primeira semana de vida (Madigan 2002).

Dentre as estruturas que compõem o cordão umbilical, somente as veias foram, de fato, passíveis de visualização plena. Assim mesmo, a sua visualização completa somente foi possível até os 14 dias de idade. As veias umbilicais foram observadas nos dois locais definidos para o exame, sendo mais difícil a visualização na posição mais distal (2 m

\begin{tabular}{|c|c|c|c|c|c|c|c|}
\hline Método e local de mensuração & & 1 dia & 7 dias & 14 dias & 21 dias & 28 dias & 35 dias \\
\hline \multicolumn{8}{|l|}{ Ultrassonografia } \\
\hline \multirow[t]{2}{*}{$2 \mathrm{~cm}$ da extremidade distal $(\mathrm{mm})$} & FIV & $14,62 \pm 3,53^{\mathrm{Aa}}$ & $13,20 \pm 2,77^{\text {Aab }}$ & $12,20 \pm 3,63^{\mathrm{Abc}}$ & $11,73 \pm 3,49^{\mathrm{Acd}}$ & $10,96 \pm 2,47^{\text {Ade }}$ & $9,87 \pm 2,55^{\mathrm{Ae}}$ \\
\hline & Nat & $11,51 \pm 3,66^{\mathrm{Ba}}$ & $10,96 \pm 4,11^{\mathrm{Bab}}$ & $8,55 \pm 3,53^{\mathrm{Bbc}}$ & $8,69 \pm 2,77^{\mathrm{Bcd}}$ & $7,93 \pm 2,33^{\text {Bde }}$ & $7,37 \pm 1,91^{\mathrm{Be}}$ \\
\hline \multirow[t]{2}{*}{ próximo ao anel umbilical (mm) } & FIV & $12,90 \pm 2,97^{\text {Аа }}$ & $12,52 \pm 2,64^{\mathrm{Aab}}$ & $12,29 \pm 3,79^{\text {Aab }}$ & $11,81 \pm 3,39^{\text {Aabc }}$ & $11,17 \pm 2,47^{\mathrm{Abc}}$ & $10,54 \pm 2,98^{\mathrm{Ac}}$ \\
\hline & Nat & $11,78 \pm 3,69^{\text {Аа }}$ & $10,57 \pm 4,04^{\mathrm{Bab}}$ & $8,90 \pm 2,63^{\mathrm{Bbc}}$ & $8,50 \pm 2,31^{\mathrm{Bcd}}$ & $7,87 \pm 2,15^{\mathrm{Bcd}}$ & $7,31 \pm 1,33^{\mathrm{Bd}}$ \\
\hline \multicolumn{8}{|l|}{ Paquimetria } \\
\hline \multirow[t]{2}{*}{$2 \mathrm{~cm}$ da extremidade distal $(\mathrm{mm})$} & FIV & $15,78 \pm 3,55^{\text {Аа }}$ & $14,15 \pm 2,58^{\mathrm{Ab}}$ & $14,15 \pm 4,04^{\mathrm{Abc}}$ & $13,35 \pm 3,36^{\text {Acd }}$ & $12,05 \pm 2,28^{\text {Ade }}$ & $11,05 \pm 1,88^{\mathrm{Ae}}$ \\
\hline & Nat & $13,10 \pm 3,55^{\mathrm{Ba}}$ & $11,80 \pm 3,86^{\mathrm{Bb}}$ & $9,50 \pm 3,33^{\mathrm{Bbc}}$ & $9,60 \pm 2,74^{\mathrm{Bcd}}$ & $9,00 \pm 2,45^{\text {Bde }}$ & $8,35 \pm 2,16^{\mathrm{Be}}$ \\
\hline \multirow[t]{2}{*}{ Próximo ao anel umbilical (mm) } & FIV & $15,85 \pm 3,54^{\mathrm{Aa}}$ & $14,15 \pm 2,37^{\mathrm{Ab}}$ & $13,95 \pm 3,75^{\mathrm{Abc}}$ & $13,35 \pm 3,41^{\mathrm{Acd}}$ & $12,95 \pm 4,36^{\text {Ade }}$ & $12,05 \pm 2,84^{\mathrm{Ae}}$ \\
\hline & Nat & $13,30 \pm 3,34^{\mathrm{Ba}}$ & $12,05 \pm 4,01^{\mathrm{Bb}}$ & $10,00 \pm 2,71^{\mathrm{Bbc}}$ & $9,95 \pm 2,31^{\mathrm{Bcd}}$ & $9,45 \pm 2,19^{\text {Bde }}$ & $8,60 \pm 1,85^{\mathrm{Be}}$ \\
\hline
\end{tabular}

\footnotetext{
$\overline{\mathrm{A}, \mathrm{B}}$ Letras maiúsculas distintas indicam diferença significativa $(\mathrm{p}<0,05)$ entre os métodos de concepção em cada idade e em cada local de mensuração.

a, b, c Letras minúsculas distintas na mesma linha indicam diferença significativa $(p<0,05)$ entre as idades.
} 


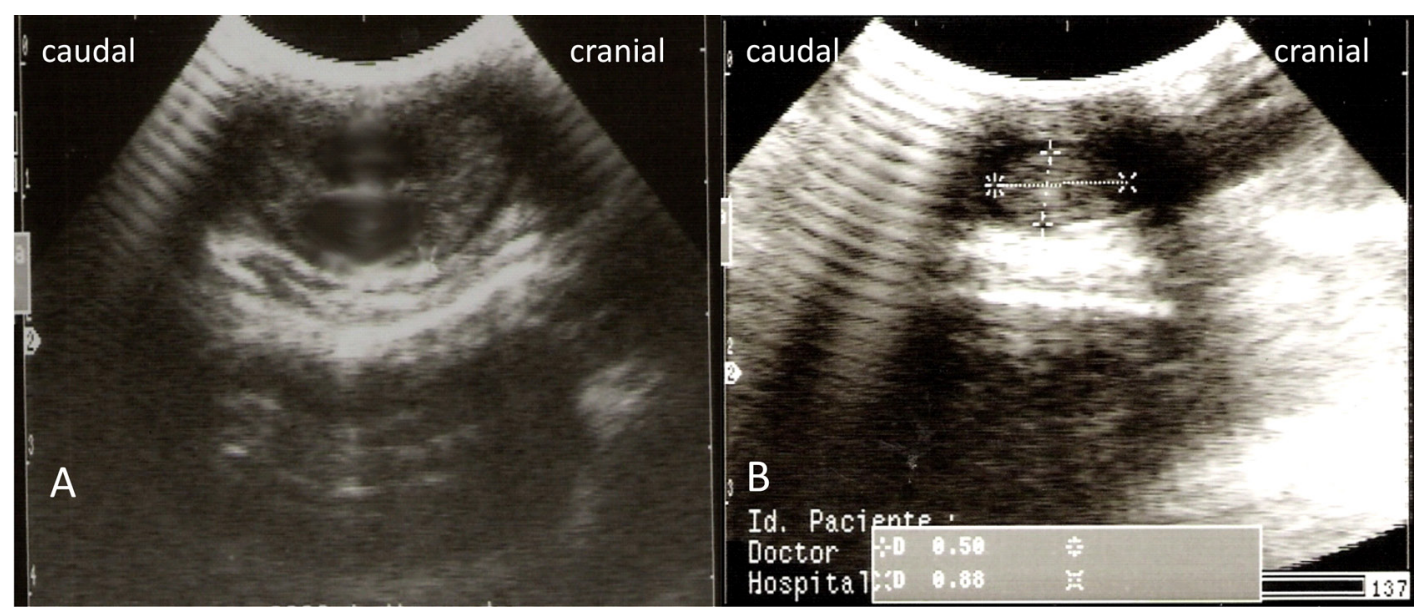

Fig.2. Corte transversal, próximo ao anel umbilical, das estruturas remanescentes do cordão umbilical que compõem o umbigo externo; demonstrando as duas veias umbilicais com lúmen anecóico em um bezerro com um dia de vida (A); e o conjunto das estruturas atrofiadas caracterizado pelo formato circular hipoecóico homogêneo circundado por uma área anecóica em um bezerro com 28 dias de vida (B). Transdutor microconvexo de 7,5 MHz.

acima da extremidade do umbigo). Nessa posição as veias não puderam ser visualizadas com detalhe em 12 bezerros recém-nascidos (oito concebidos naturalmente e quatro produtos de PIVE). As veias foram identificadas como duas estruturas contíguas com formato circular ou ovalado, parede hiperecóica e lúmen anecóico (Fig.2). Em cinco animais produtos de PIVE e em quatro bezerros concebidos por métodos naturais observou-se apenas um lúmen na posição próxima ao anel umbilical. Nesses mesmos animais os dois lúmens foram visualizados na posição mais distal (2 $\mathrm{cm}$ acima da extremidade do umbigo). Isso indica que, na maioria dos bezerros, as veias umbilicais se fusionam, originando um vaso único, próximo à sua entrada na cavidade abdominal. Em alguns bezerros, contudo, a fusão acontece em posição mais distal. 0 ducto alantóide e as artérias foram difícil e raramente identificados, mesmo nos animais recém-nascidos e apenas foi observado o espaço remanescente destas estruturas com característica hipoecogênica, conforme descrito por Watson et al. (1994).

A involução natural das estruturas umbilicais extracavitárias com o avançar da idade tornou a visualização ultrassonográfica mais difícil. A partir dos 14 dias de vida já não se observaram mais os lúmens anecóicos das veias e os vasos que compõem o cordão umbilical apareceram como uma estrutura única sem lúmen mais ecogênica e com presença de área anecóica ao seu redor (Fig.2). Essas observações são semelhantes às de Watson et al. (1994) em bezerros da raça Holandesa.

0 exame por imagem nos dois locais distintos definidos para o estudo (próximo ao anel umbilical e $2 \mathrm{~cm}$ acima da extremidade distal do umbigo) foi mais produtivo durante as duas primeiras semanas de vida. Nas semanas subsequentes, a avaliação realizada próximo ao anel umbilical é suficiente, a menos que a palpação prévia do umbigo indique a necessidade de examinar estruturas alteradas em localização mais distal. A paquimetria deve ser considerada útil para avaliação da involução do umbigo, mas não substitui a ultrassonografia que permite a avaliação topográfica das estruturas pertencentes a esta região e maior acurácia diagnóstica.

Com relação às estruturas umbilicais intracavitárias, compreendendo a veia umbilical, as duas artérias umbilicais (direita e esquerda) e o ducto alantóide, a avaliação por palpação abdominal profunda foi sempre realizada antecedendo o exame ultrassonográfico. A identificação da veia umbilical foi possível por palpação em todos os bezerros até os 14 dias de idade. Após essa idade foi impossível palpá-la na maioria dos animais. Quase toda a sua extensão era palpada, desde o umbigo até próximo ao fígado, posição em que as últimas costelas provocavam impedimento físico. Era percebida como uma estrutura de formato cilíndrico, com paredes definidas e de consistência flácida. A repleção do abomaso com conteúdo alimentar pode ser apontada como o fator que provocou a maior dificuldade para o sucesso do exame por palpação.

A partir do umbigo em direção à bexiga, o conjunto composto pelas duas artérias umbilicias e pelo ducto alantóide, posicionado entre as mesmas, foi palpado com sucesso em todos os bezerros somente até os 14 dias de idade, apresentando consistência flácida e formato oval. Era percebido como uma estrutura única, sendo impossível individualizar os seus três componentes. Aos 21 dias de vida essa estrutura já não era palpada na maioria dos bezerros. Em todo o seu trajeto na posição lateralmente à bexiga, as artérias direita e esquerda eram facilmente palpadas até os 21 dias, possuindo consistência um pouco mais rígida e formato cilíndrico. Esse exame era sempre facilitado quando a bexiga estava repleta, mas era possível mesmo com o órgão vazio. A palpação do ducto alantóide como uma estrutura individualizada, de fato, nunca foi bem sucedida nos bezerros estudados.

Comparado à palpação, o exame ultrassonográfico das estruturas umbilicais abdominais deve ser considerado um método mais valioso para fins diagnósticos. Com exceção do ducto alantóide, a veia e a artéria umbilicais foram facilmente visualizadas em todos os locais definidos para 
Quadro 2. Diâmetro $(\overline{\mathrm{x}} \pm \mathbf{s})$ das estruturas umbilicais abdominais mensurado por ultrassonografia em bezerros sadios da raça Nelore concebidos naturalmente (Nat) ou por produção in vitro de embriões (PIVE), entre o nascimento e 35 dias de vida

\begin{tabular}{|c|c|c|c|c|c|c|c|}
\hline Estrutura e local de mensuração & & 1 dia & 7 dias & 14 dias & 21 dias & 28 dias & 35 dias \\
\hline \multicolumn{8}{|l|}{ Veia umbilical (mm) } \\
\hline \multirow[t]{2}{*}{ Próximo ao anel umbilical } & FIV & $5,64 \pm 2,22^{\mathrm{Aa}}$ & $4,22 \pm 1,61^{\mathrm{Ab}}$ & $3,60 \pm 1,34^{\mathrm{Ab}}$ & $2,76 \pm 0,58^{\mathrm{Ac}}$ & $2,21 \pm 0,52^{\mathrm{Ac}}$ & $1,50 \pm 0,65^{\mathrm{Ad}}$ \\
\hline & Nat & $3,12 \pm 0,99$ ва & $2,48 \pm 0,54$ Bab & $2,30 \pm 0,39^{\mathrm{Bb}}$ & $2,09 \pm 0,46^{\mathrm{Bb}}$ & $1,74 \pm 0,33 \mathrm{Abc}$ & c $1,32 \pm 0,25 \mathrm{Ac}$ \\
\hline \multirow[t]{2}{*}{ Entre o anel umbilical e o fígado } & FIV & $7,54 \pm 1,42^{\text {Аa }}$ & $5,26 \pm 0,93 \mathrm{Ab}$ & $4,50 \pm 0,59 \mathrm{Ac}$ & $3,63 \pm 0,61^{\mathrm{Ad}}$ & $2,82 \pm 0,70 \mathrm{Ae}$ & $1,88 \pm 0,65 \mathrm{Af}$ \\
\hline & Nat & $5,70 \pm 1,34$ ва & $4,45 \pm 0,75^{\mathrm{Bb}}$ & $4,10 \pm 0,41^{\mathrm{Ab}}$ & $3,44 \pm 0,53^{\mathrm{Ac}}$ & $2,85 \pm 0,58^{\mathrm{Ac}}$ & $1,88 \pm 0,37^{\mathrm{Ad}}$ \\
\hline \multirow[t]{2}{*}{ Na chegada ao fígado } & FIV & $7,33 \pm 1,46^{\text {Aa }}$ & $5,18 \pm 1,16^{\mathrm{Ab}}$ & $4,51 \pm 0,90^{\mathrm{Ac}}$ & $3,42 \pm 0,67^{\mathrm{Ad}}$ & $2,66 \pm 0,50^{\mathrm{Ae}}$ & $1,90 \pm 0,72^{\mathrm{Af}}$ \\
\hline & Nat & $6,00 \pm 1,11$ ва & $4,41 \pm 0,47^{\mathrm{Bb}}$ & $4,05 \pm 0,49^{\mathrm{Ab}}$ & $3,44 \pm 0,56^{\mathrm{Ac}}$ & $2,85 \pm 0,56^{\text {Acd }}$ & $1,99 \pm 0,41 \mathrm{Ad}$ \\
\hline \multirow[t]{2}{*}{ Dentro do fígado } & FIV & $8,03 \pm 1,42^{\text {Аа }}$ & $5,51 \pm 0,91^{\mathrm{Ab}}$ & $4,94 \pm 0,80^{\mathrm{Ab}}$ & $3,97 \pm 0,72^{\mathrm{Ac}}$ & $3,11 \pm 0,62^{\mathrm{Ad}}$ & $2,18 \pm 0,61^{\mathrm{Ae}}$ \\
\hline & Nat & $6,45 \pm 1,00^{\mathrm{Ba}}$ & $5,05 \pm 0,69 \mathrm{Ab}$ & $4,35 \pm 0,48 \mathrm{Bc}$ & $3,84 \pm 0,75^{\mathrm{Ac}}$ & $3,01 \pm 0,63^{\mathrm{Ad}}$ & $2,16 \pm 0,39 \mathrm{Ae}$ \\
\hline \multicolumn{8}{|l|}{ Artéria umbilical esquerda (mm) } \\
\hline \multirow[t]{2}{*}{ Lateralmente à bexiga } & FIV & $8,14 \pm 1,15^{\text {Аа }}$ & $5,67 \pm 1,31^{\mathrm{Ab}}$ & $4,84 \pm 0,90 \mathrm{Ac}$ & $3,92 \pm 0,81^{\mathrm{Ad}}$ & $2,98 \pm 0,65^{\mathrm{Ae}}$ & $2,03 \pm 0,54 \mathrm{Af}$ \\
\hline & Nat & $6,92 \pm 1,49$ ва & $5,47 \pm 0,71^{\mathrm{Ab}}$ & $4,80 \pm 0,78^{\mathrm{Ab}}$ & $3,58 \pm 0,76^{\mathrm{Ac}}$ & $2,58 \pm 0,56^{\mathrm{Ad}}$ & $2,07 \pm 0,32 \mathrm{Ad}$ \\
\hline \multirow[t]{2}{*}{ No pólo da bexiga } & FIV & $6,95 \pm 1,02^{\text {Аa }}$ & $5,00 \pm 1,09 \mathrm{Ab}$ & $4,21 \pm 0,86^{\mathrm{Ac}}$ & $3,29 \pm 0,56^{\mathrm{Ad}}$ & $2,56 \pm 0,66^{\mathrm{Ae}}$ & $1,74 \pm 0,53 \mathrm{Af}$ \\
\hline & Nat & $5,81 \pm 1,08$ Ba & $4,63 \pm 0,76^{\mathrm{Ab}}$ & $4,00 \pm 0,73^{\mathrm{Ac}}$ & $3,19 \pm 0,76^{\mathrm{Ad}}$ & $2,26 \pm 0,58 \mathrm{Ae}$ & $1,73 \pm 0,39 \mathrm{Ae}$ \\
\hline \multirow[t]{2}{*}{$2 \mathrm{~cm}$ caudais ao anel umbilical } & FIV & $4,82 \pm 1,68$ Аа & $4,01 \pm 1,48^{\mathrm{Ab}}$ & $3,21 \pm 0,72 \mathrm{Ac}$ & $2,41 \pm 0,59$ Ad & $1,94 \pm 0,59$ Ade & e $1,33, \pm 0,41^{\mathrm{Ae}}$ \\
\hline & Nat & $3,56 \pm 0,97$ ва & $2,76 \pm 0,53 \mathrm{Bb}$ & $2,40 \pm 0,48^{\mathrm{Bbc}}$ & $2,03 \pm 0,54 \mathrm{Ac}$ & $1,47 \pm 0,38$ Acd & $1,32 \pm 0,30 \mathrm{Ad}$ \\
\hline \multicolumn{8}{|l|}{ Ducto Alantóide (mm) } \\
\hline \multirow[t]{2}{*}{ No pólo cranial da bexiga } & FIV & $3,99 \pm 1,04^{\text {Аa }}$ & $2,85 \pm 1,10^{\mathrm{Ab}}$ & & & & \\
\hline & Nat & $3,50 \pm 1,01^{\mathrm{Aa}}$ & $2,45 \pm 0,70^{\mathrm{Aa}}$ & $1,60 \pm 0,40$ & & & \\
\hline \multirow[t]{2}{*}{$1 \mathrm{~cm}$ cranial ao pólo da bexiga } & FIV & $3,20 \pm 0,83^{\text {Аа }}$ & $2,36 \pm 1,06^{\mathrm{Ab}}$ & & & & \\
\hline & Nat & $2,62 \pm 0,77$ ва & $1,79 \pm 0,52^{\mathrm{Bb}}$ & $1,30 \pm 0,32$ & & & \\
\hline \multirow[t]{2}{*}{$5 \mathrm{~cm}$ craniais ao pólo da bexiga } & FIV & $2,76 \pm 0,77^{\text {Аа }}$ & $1,89 \pm 0,80^{\mathrm{Ab}}$ & & & & \\
\hline & Nat & $2,17 \pm 0,61 \mathrm{Ba}$ & $1,43 \pm 0,37^{\mathrm{Ab}}$ & $1,1 \pm 0,33$ & & & \\
\hline \multirow[t]{2}{*}{$2 \mathrm{~cm}$ caudais ao anel umbilical } & FIV & $2,08 \pm 0,57$ Аа & $1,23 \pm 0,43^{\mathrm{Ab}}$ & & & & \\
\hline & Nat & $1,67 \pm 0,46^{\mathrm{Ba}}$ & $1,13 \pm 0,17^{\mathrm{Ab}}$ & $0,90 \pm 0,19$ & & & \\
\hline
\end{tabular}

realização do exame, e em todos os bezerros estudados até os 35 dias de idade (Quadro 2). Independente da estrutura e do local avaliados, os efeitos da idade e do método de concepção e a interação entre os dois fatores provaram-se significativos $(p<0,05)$, mas não o efeito do sexo $(p>0,05)$.

A veia umbilical foi escaneada em quatro locais distintos desde a proximidade do anel umbilical até o fígado (logo antes da sua bifurcação dentro do parênquima hepático) e isso é importante, durante e realização do seu exame por imagem, porque os processos patológicos que a acometem não obrigatoriamente estarão presentes em toda a sua extensão. De forma geral e independente do local examinado, o diâmetro da veia se reduziu gradativamente com o avançar da idade (Quadro 2), como resultado do processo natural de involução dessa estrutura que não tem finalidade na vida extrauterina e dará origem ao ligamento redondo do fígado (Habel 1986, Noden \& Lahunta 2001).

Os valores médios obtidos para o diâmetro da veia umbilical somente podem ser comparados com os observados por Lischer \& Steiner (1993) e por Watson et al. (1994) pois esses são os únicos trabalhos publicados nos quais se realizaram mensurações dos vasos umbilicais em bezerros sadios empregando-se a ultrassonografia. Em comparação aos bezerros Nelore estudados, os de raças taurinas examinados em ambos os estudos anteriores nasceram com a veia umbilical mais calibrosa (com diâmetro 0,5-1cm maior) e essa diferença se manteve até os 14 ou 21 dias. Nos bezerros Holandeses (Watson et al. 1994), os diâmetros obtidos eram parecidos com os do presente trabalho aos 21 dias de vida sugerindo uma involução mais rápida a partir dos 14 dias. Outra característica que indica distinções morfológicas entre as raças é o fato de a veia possuir um lúmen menor próximo ao anel umbilical no bezerro Nelore recém-nascido. Nos bezerros taurinos observou-se exatamente o contrário, o diâmetro não variava ao longo do trajeto até o fígado, mas era muito maior próximo à sua entrada no abdome.

A visualização da veia umbilical com imagem definida foi bem sucedida em todos os bezerros estudados, nas diferentes idades e em todos os quatro locais em que a veia foi escaneada (Fig.3). A dificuldade para obter uma imagem adequada esteve relacionada com a redução do diâmetro da veia e isso explica a maior dificuldade do exame nos bezerros com 35 dias de idade, particularmente na posição próxima ao anel umbilical. A visualização nas posições entre o anel umbilical e o fígado e próximo ao fígado foi sempre fácil até os 35 dias. 0 exame da veia na sua posição interna no parênquima hepático era fácil até os 21 dias de idade. Por causa do crescimento dos bezerros, aos 28 e aos 35 dias de idade havia a necessidade de posicionar o transdutor pressionando a parede abdominal por baixo da última costela. Watson et al. (1994) relataram maior dificuldade para obterem imagens da veia umbilical, tendo sido impossível o exame em alguns bezerros a partir de segunda semana de vida. Deve-se considerar que esses autores realizaram a ultrassonografia com os bezerros contidos em estação. É coerente admitir, portanto, que a contenção em decúbito lateral direito seja mais apropriada para a execução do exame.

Qualquer que tenha sido o local definido para o exame, 


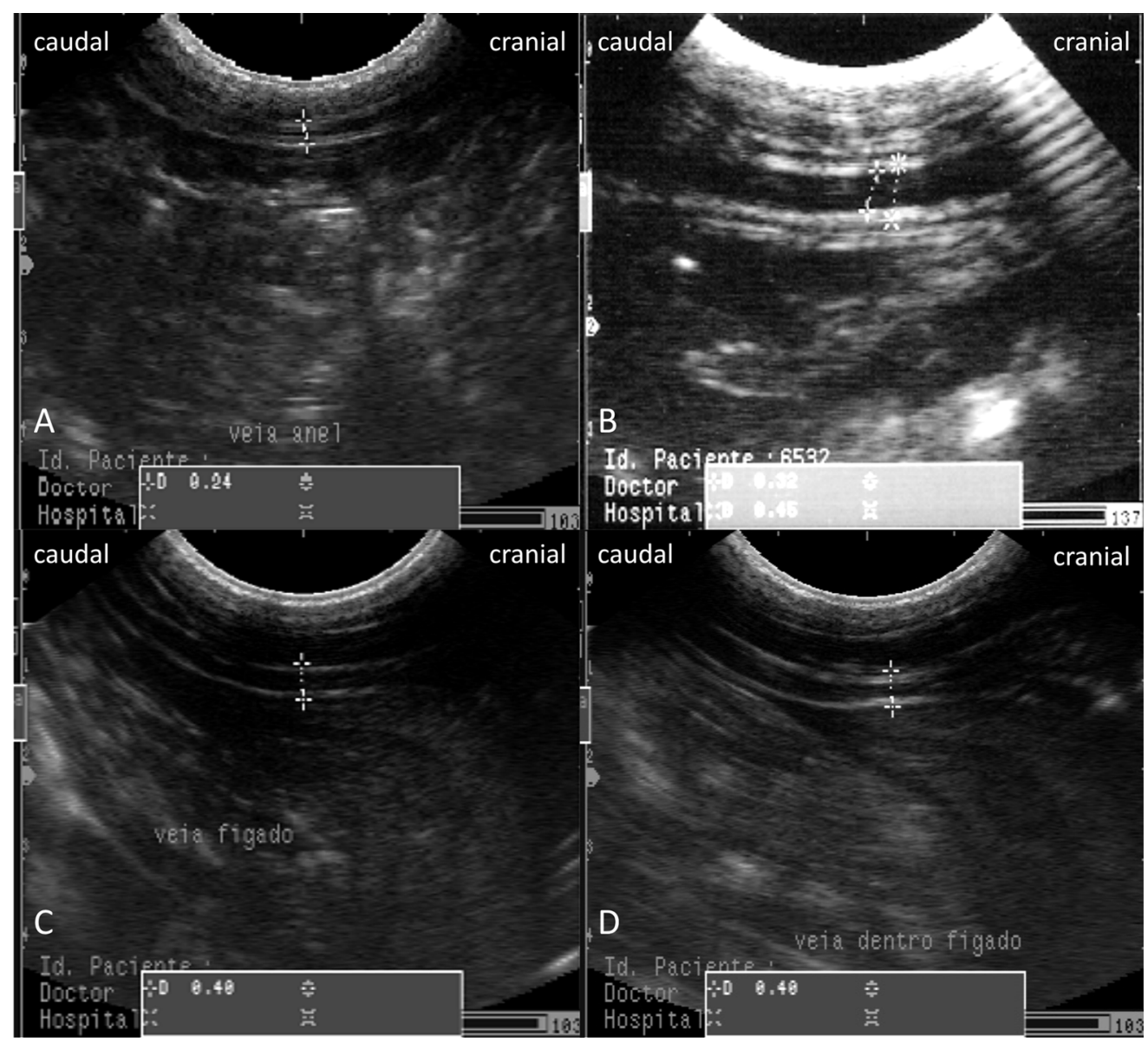

Fig.3. Cortes longitudinais da veia umbilical. (A) Próximo ao anel umbilical em um bezerro com 21 dias de vida demonstrando as paredes hipoecóicas e o lúmen anecóico estreitado. (B) Entre o anel umbilical e o fígado em um bezerro com um dia de vida; pode-se observar toda a extensão da veia com paredes hiperecóicas e lúmen anecóico. (C) Na chegada ao fígado em um bezerro com sete dias de vida; pode-se observar o parênquima hepático em situação cranial. (D) Dentro do parênquima hepático antes da sua bifurcação em um bezerro com 21 dias de vida. Transdutor microconvexo de 7,5 MHz.

a veia foi sempre identificada com a presença das duas paredes hiperecóicas separadas pelo lúmen homogeneamente anecóico (Fig.3). A parede apresentava 0,3 a $0,7 \mathrm{~mm}$ de espessura ao longo de todo o seu trajeto sem variação, era regular e contínua. A ecogenicidade da parede tendeu a aumentar com o avançar da idade em proporção com a redução da luz do vaso em processo de involução. Não se observou a dificuldade relatada por Lischer \& Steiner (1993) relacionada à impossibilidade de distinguir a parede da veia umbilical dentro do parênquima hepático nos bezerros a partir do final da segunda semana de vida. Nos bezerros Nelore estudados, independente da idade, as paredes da veia umbilical eram facilmente identificadas com ecogenicidade maior do que a do tecido hepático (Fig.3). 0 incremento na qualidade das imagens ultrassonográficas, devido ao aumento da resolução dos aparelhos e à inclusão de novos recursos, ocorrido ao longo do tempo pode explicar a discrepância entre as observações dos estudos.

De maneira semelhante ao que se observou para a veia, a luz da artéria umbilical esquerda se reduziu continuamente ao longo do primeiro mês de vida (Quadro 2), caracterizando o processo fisiológico de atrofia desse vaso, o qual, completamente involuído originará o ligamento lateral da bexiga posteriormente (Gloshal 1986, Noden \& Lahunta 2001). A artéria esquerda foi escaneada inicialmente na sua posição lateralmente à bexiga, local em que é mais facilmente identificada e que serviu de ponto de referência. E a sua imagem foi acompanhada ao longo do seu trajeto até a proximidade do anel umbilical. As mensurações do diâmetro do vaso foram realizadas em três locais: lateral à bexiga, próximo ao pólo cranial da bexiga e $2 \mathrm{~cm}$ caudal ao anel umbilical. Durante a realização desses procedimentos, o conjunto composto pelas duas artérias e pelo ducto alantóide em posição centralizada, o qual se estende desde $o$ anel umbilical até a bexiga, foi examinado sistematicamente em todos os bezerros estudados. Dessa forma, embora o diâmetro da artéria umbilical direita não tenha sido mensurado, esse vaso também foi avaliado ao longo do seu trajeto do umbigo até a bexiga.

A artéria apresentou diâmetro parecido com o da veia umbilical, possuía luz menor próximo ao anel umbilical, e era um pouco mais calibrosa na posição lateral à bexiga logo após o nascimento (Quadro 2). Os diâmetros obtidos nos bezerros Nelore são 0,5 a $1,5 \mathrm{~cm}$ menores dos que os apontados em bezerros taurinos (Lischer \& Steiner 1993, Watson et al. 1994), o que caracteriza diferenças relacionadas à raça. Merece destaque o fato de as artérias terem sido visualizadas com facilidade, em todos os bezerros, na sua posição mais próxima possível ao anel umbilical. Isso contraria o conceito de que com o rompimento do cordão umbilical após o nascimento as artérias se retraem imediatamente para o interior da cavidade abdominal e as suas extremidades se distanciam do anel umbilical (Noden \& Lahunta 2001, Nuss 2007).

A imagem com boa definição da artéria umbilical foi obtida em todos os bezerros estudados, nas diferentes ida- 
des e em todos os três locais em que a artéria foi escaneada (Fig.4). A redução do diâmetro aos 35 dias de idade criava dificuldade natural para o exame. Deve-se destacar que o grau de repleção da bexiga com urina apresentou-se como o fator crítico determinante da facilidade para realizar o exame da artéria. Por causa da ausência de contraste adequado, quando a bexiga estava vazia era muito mais difícil identificar a artéria umbilical em sua posição lateral ao órgão. E como esse era o ponto inicial de referência, todo o exame do vaso ficava comprometido. Nesses casos houve a necessidade de retardar o exame e aguardar que certo volume de urina se acumulasse no interior da bexiga. Esse problema foi mais comum no caso de alguns bezerros machos provenientes de PIVE, mais mansos e acostumados com o contato com o homem. Era comum que urinassem tão logo fosse iniciada a manipulação da região umbilical, contígua ao prepúcio.

À semelhança da veia umbilical, a artéria sempre foi identificada com a presença das duas paredes hiperecóicas regulares e contínuas separadas pelo lúmen homogeneamente anecóico. A parede apresentava espessura de 0,2 a
$0,4 \mathrm{~mm}$ em toda a sua extensão da bexiga ao anel umbilical, porém era mais espessa $(0,8 \mathrm{~mm})$ e ecogênica na sua posição lateral à bexiga. Nessa mesma posição, mas somente nela, foi digna de nota a observação de conteúdo hipoecogênico na luz do vaso, sem formato ou tamanho definido (Fig.4). Esse achado foi mais comum nos bezerros até 14 dias de idade e não foi relatado nos estudos anteriores (Lischer \& Steiner 1993, Watson et al. 1994).

Das três estruturas examinadas, o ducto alantóide apresentou-se como a mais difícil de ser avaliada. Em todos os 40 bezerros estudados só foi possível visualizá-lo com uma imagem de boa qualidade até os sete dias de vida (Quadro 2). Aos 14 dias de idade a imagem ainda era confiável em 17 bezerros concebidos naturalmente, mas somente em quatro dos produtos de PIVE. Lischer \& Steiner (1993) e Watson et al. (1994) não conseguiram realizar mensurações do ducto alantóide em praticamente nenhum dos bezerros taurinos sadios que examinaram, até mesmo nos recém-nascidos. Apesar do ducto alantóide possuir parede mais delgada do que a veia e as artérias, até os sete dias de idade era possível obter uma imagem bem definida porque

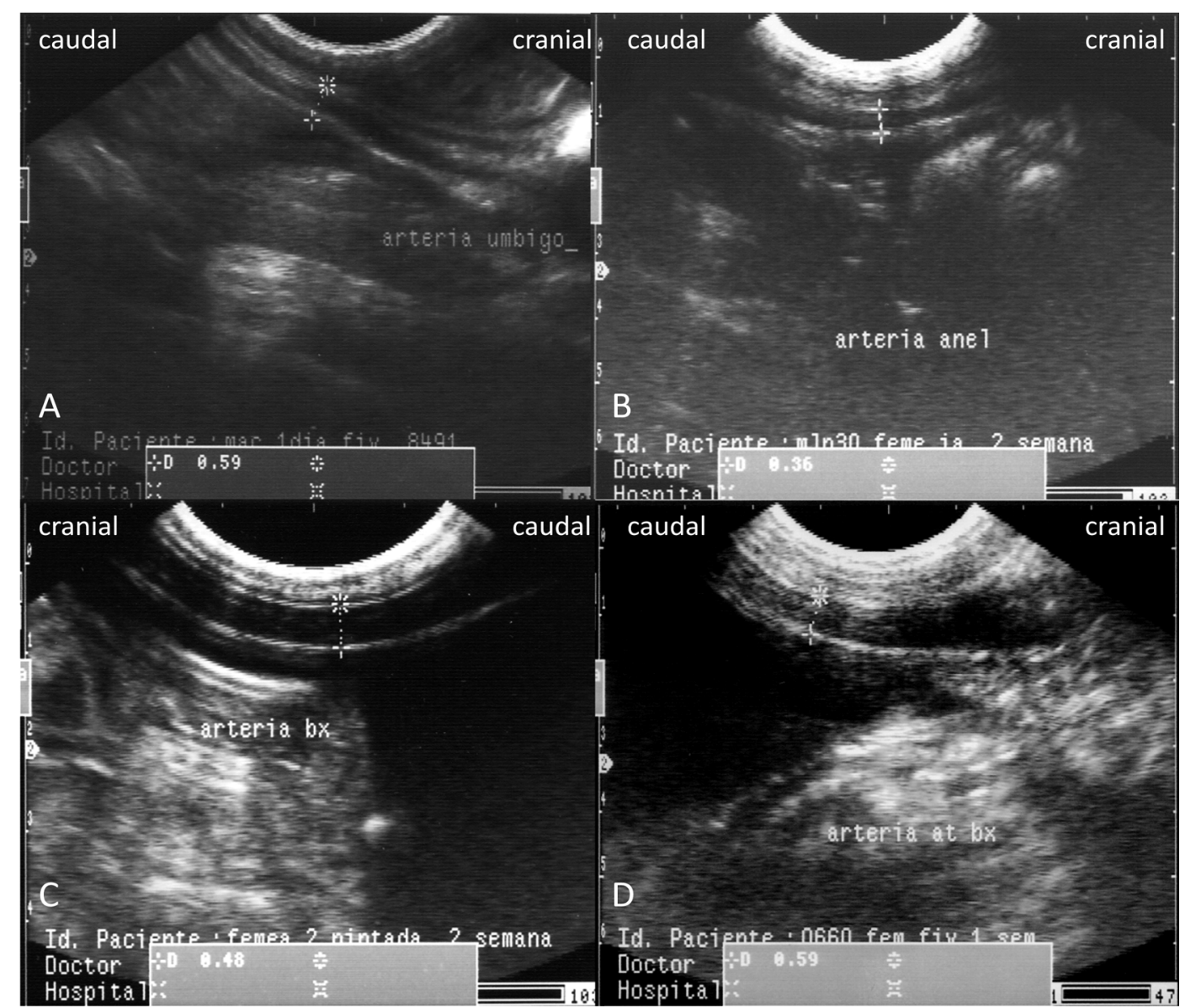

Fig.4. Cortes longitudinais da artéria umbilical esquerda. (A) Próximo ao anel umbilical em um bezerro com um dia de vida; podem-se observar as paredes hiperecóicas e o lúmen anecóico e a presença da artéria umbilical direita na situação mais próxima ao anel umbilical. (B) Próximo ao anel umbilical em um bezerro com 14 dias de vida. (C) No pólo cranial da bexiga (bx) em um bezerro com 14 dias de vida; observa-se a bexiga em situação caudal e a artéria umbilical direita em situação ventral. (D) Lateralmente à bexiga em um bezerro com sete dias de vida; observa-se a bexiga em situação ventral e conteúdo hipoecogênico na luz do vaso, sem formato ou tamanho definido. Transdutor microconvexo de 7,5 $\mathrm{MHz}$. 
a ecogenicidade da sua parede se assemelhava à da parede dos vasos. Como ocupa posição intermediária entre as duas artérias umbilicais, direita e esquerda, em toda a sua extensão do pólo cranial da bexiga até o anel umbilical, as imagens da bexiga e das duas artérias serviam de referência obrigatória para a visualização do ducto alantóide. Por causa da redução do seu diâmetro, a partir dos 14 dias de vida a sua visualização ficava impossibilitada.

O seu lúmen era maior no pólo cranial da bexiga e menor próximo ao anel umbilical. Possuía menor diâmetro que a veia e que as artérias desde o nascimento (Quadro 2), e o lúmen se reduziu com o avançar da idade. Essa estrutura completamente atrofiada dá origem ao ligamento central da bexiga (Gloshal 1986, Noden \& Lahunta 2001). Era visto como uma estrutura composta por duas paredes lisas, regulares e contínuas, hiperecóicas separadas pelo lúmen homogeneamente anecóico. As paredes possuíam espessura menor do que as da veia e da artéria (Fig.5).

O pólo cranial da bexiga, que possui formato cônico no bezerro recém-nascido porque é uma continuação da bexiga com o ducto alantóide, era o ponto de referência mais importante para a identificação e exame visual dessa estrutura umbilical (Fig.5). 0 exame era procedido a partir desse ponto acompanhando toda a sua extensão até o anel umbilical. Nos bezerros com 14 dias de idade a extremidade cranial da bexiga já possuía a sua silhueta arredondada perdendo-se, assim, o ponto de referência para visualizar o ducto alantóide. Assim como comentado para a artéria umbilical em sua posição lateral à bexiga, o exame do ducto alantóide ficava muito prejudicado quando a bexiga estava vazia.

Tanto o conjunto das estruturas remanescentes do cordão umbilical, componente do umbigo externo, quanto as três estruturas umbilicais intracavitárias estudadas (veia, artéria e ducto alantóide), apresentaram-se mais calibrosas $(\mathrm{p}<0,05)$ nos bezerros produtos de PIVE recém-nascidos do que naqueles concebidos por método natural (Quadros 1 e 2). Essa diferença manteve-se presente durante todo o primeiro mês de vida no caso do umbigo externo; a veia e a artéria mantiveram-se mais calibrosas somente até os 14 dias de vida; e o ducto alantóide possuía maior diâmetro somente ao nascimento. A evidência de que bezerros produtos de PIVE são comumente acometidos por doenças umbilicais, especialmente a persistência do ducto alantóide (Rodrigues et al. 2010), poderia estar supostamente relacionada ao maior calibre das estruturas umbilicais, condição observada na prática rotineira com esses animais. Deve-se considerar, contudo, que nos produtos de PIVE recém-nascidos estudados, as estruturas abdominais possuíam diâmetro médio somente 1 a $2 \mathrm{~mm}$ maior e a involução das mesmas ocorreu de forma semelhante à dos demais bezerros. Mesmo no caso do umbigo externo, a espessura média chegou a ser, no máximo, $3 \mathrm{~mm}$ maior somente. As diferenças observadas entre os bezerros produtos de PIVE e os concebidos naturalmente foram, portanto, de magnitude muito reduzida, o que certamente não poderia contribuir para maior suscetibilidade às onfalopatias. Dentre os bezerros inicialmente incluídos no estudo, seis produtos de PIVE e dois frutos de concepção natural foram descartados posteriormente e substituídos porque desenvolveram doença umbilical: cinco onfalites; duas onfaloarterites e uma onfaloflebite, conforme a classificação de Figueirêdo (1999). Na propriedade onde se realizou o estudo, a prevalência das doenças umbilicais era reduzida, de forma geral, independente do método de concepção adotado.

Apesar de ser um assunto ainda não completamente esclarecido, algumas causas são apontadas para a ocorrência do nascimento de bezerros de tamanho grandes ou gigantes no caso da PIVE ou dos bezerros clonados. A morfologia diferenciada da placenta pode contribuir para isso (Bertolini \& Anderson 2002, Farin et al. 2006, 2010) e suspeita-se do efeito da exposição dos oócitos e dos embriões a componentes de enriquecimento empregados na composição dos meios de cultura utilizados para a manipulação dos mesmos (Behboodi et al. 1995, Young et al. 1998, Jacobsen et al. 2000). As alterações morfológicas do sistema circulatório,
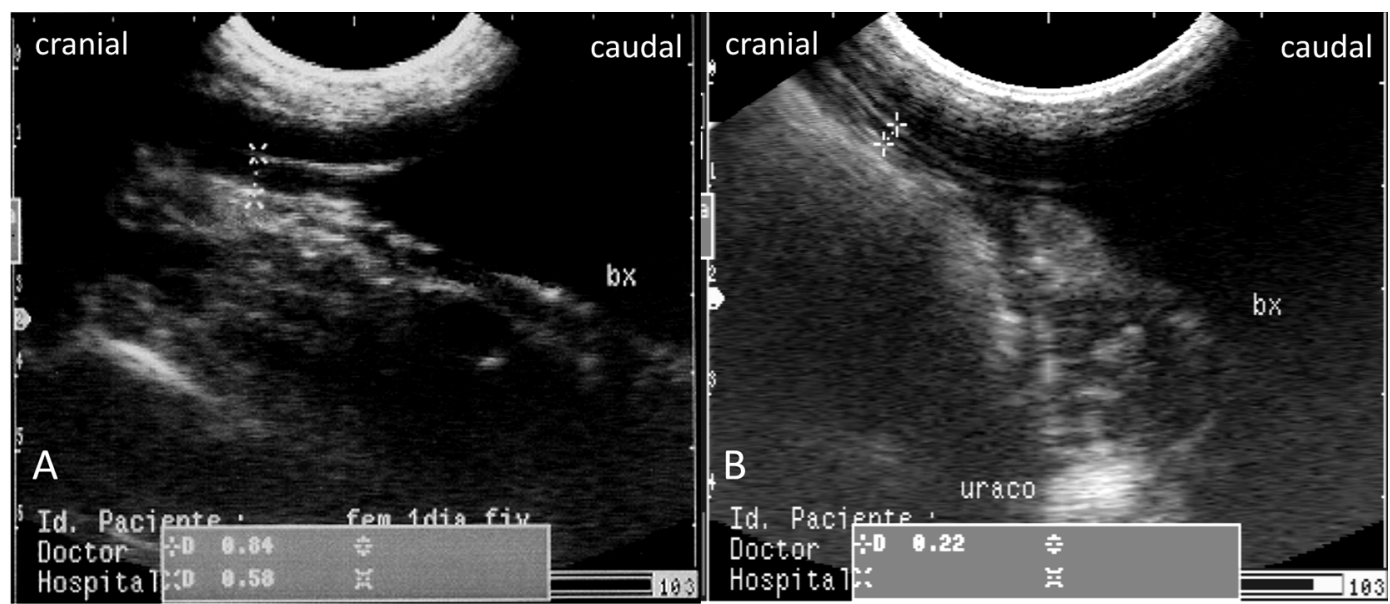

Fig.5. Cortes longitudinais do ducto alantóide. (A) No pólo cranial da bexiga em um bezerro com um dia de vida; notam-se paredes hiperecóicas com lúmen anecóico como uma estrutura que se continua do pólo cranial da bexiga, de formato cônico. (B) Um centímetro cranialmente à bexiga em um bezerro com um dia de vida; nota-se a luz estreita da estrutura. Em ambas a imagens a bexiga (bx) se apresenta em situação caudal e a artéria umbilical esquerda aparece dorsalmente. Transdutor microconvexo de 7,5 MHz. 
aliadas ao gigantismo, são bem caracterizadas nos bezerros clonados, assim como o maior tamanho dos vasos umbilicais e a maior incidência de doenças envolvendo essas estruturas (Garry et al. 1996, Batchelder et al. 2007, Miglino et al. 2007, Meirelles et al. 2010). Nos produtos de PIVE isso não está bem elucidado. De qualquer forma, observa-se na prática que o nascimento de bezerros grandes concebidos in vitro é menos frequente atualmente do que foi em anos passados e isso se deve, provavelmente, ao aprimoramento das técnicas laboratoriais empregadas.

Uma dificuldade técnica importante observada na realização do exame ultrasonográfico, tanto do umbigo externo quanto das estruturas abdominais, estava relacionada à má qualidade da imagem nos bezerros recém-nascidos devido à presença de grande quantidade de artefatos. Isso foi atribuído, supostamente, à presença de líquido amniótico ressecado impregnando os pêlos, os quais se apresentavam aglutinados e endurecidos. Esse tipo de dificuldade já não estava presente no sétimo dia de vida. A aplicação tópica de maior volume de álcool, a remoção do excesso e de sujidades com papel toalha, a nova aplicação de álcool e a aplicação do gel na superfície ainda umedecida pelo álcool foram providências bem sucedidas para melhorar a qualidade da imagem nos recém-nascidos.

É ainda relevante apontar que contrariamente ao que se preconiza como a melhor técnica possível, a tricotomia não foi realizada nos bezerros estudados anteriormente ao exame ultrassonográfico porque, por motivos estéticos, não houve permissão para tal. A solução encontrada para contornar essa dificuldade foi a manutenção da pele e dos pêlos da região abdominal úmidos durante todo o período da execução do exame. 0 uso de álcool ( $50^{\circ}$ GL) e de gel (1:2) diluídos com água destilada provou-se completamente adequado para o melhor acoplamento acústico, eliminando a interferência provocada pelos pêlos. Esse procedimento foi bem sucedido independentemente da idade do bezerro. Sempre que necessário realizavam-se aplicações complementares do gel. Sob condições ideais a depilação deve ser realizada para garantir a qualidade superior da imagem. Porém, nas situações em que ela estiver impossibilitada, a alternativa empregada nesse estudo pode dar bons resultados, pelo menos nos bezerros zebuínos que, ao contrário dos taurinos, possuem pêlos curtos.

Em síntese, o presente trabalho representa contribuição original por apresentar resultados inéditos em bezerros da raça zebuína, podendo-se concluir que a ultrassonografia é um método apropriado para a realização do exame das estruturas umbilicais extracavitárias e abdominais dos bezerros da raça Nelore. Sob condições fisiológicas, a veia e a artéria umbilicais são visualizadas até os 35 dias de idade e o ducto alantóide durante a primeira semana de vida. 0 diâmetro das estruturas umbilicais se reduz continuamente após o nascimento e, nos recém-nascidos, o das estruturas que compõem o umbigo externo não deve ultrapassar $2 \mathrm{~cm}$, os da veia e da artéria podem chegar a $1 \mathrm{~cm}$ e o do ducto alantóide é próximo a $0,5 \mathrm{~cm}$. Comparados aos bezerros concebidos por métodos naturais, os produtos de fertilização in vitro nascem com os vasos umbilicais e o ducto alantóide um pouco mais calibrosos (diâmetros 1 a $3 \mathrm{~mm}$ maiores), diferença que provavelmente é insuficiente para causar impactos sobre a saúde dos mesmos.

\section{REFERÊNCIAS}

Assis Neto A.C., Pereira F.T., Santos T.C., Ambrósio C.E., Leiser R. \& Miglino M.A. 2010. Morpho-physical recording of bovine conceptus (Bos indicus) and placenta from days 20 to 70 of pregnancy. Reprod. Domest. Anim. 45(5):760-772.

Batchelder C.A., Bertoloni M., Mason J.B., Moyer A.L., Hoffert K.A., Petkov S.G., Famula T.R., Angelos J., George L.W. \& Anderson G. B. 2007. Perinatal Physiology in cloned and normal calves: physical and clinical characteristic. Cloning Stem Cells 9(1):63-82.

Baxter G.M. 1989. Umbilical masses in calves: diagnosis, treatment, and complications. Compend. Contin. Educ. Pract. Vet. 11(4):505-513.

Behboodi E., Anderson G.B., Bondurant R.H., Cargill S.L., Kreuscher B.R., Medrano J.F. \& Murray J.D. 1995. Birth of large calves that developed from in vitro-derived bovine embryos. Theriogenology 44(2):227232.

Bertolini M. \& Anderson G.B. 2002. The placenta as a contributor to production of large calves. Theriogenology 57(1):181-187.

Biondo A.W., Lopes S.T.A., Kohayagawa A., Takahira R.K. \& Alencar N.X. 1998. Hemograma de bovinos (Bos indicus) sadios da raça Nelore no primeiro mês de vida, criados no estado de São Paulo. Ciência Rural 28(2):251-256.

Bouckaert J.H. \& De Moor A. 1965. Surgical treatment of umbilical infections in calves. Vet. Rec. 77(27):771-774.

Coles E.H. 1986a. Leucócitos, p.15-71. In: Ibid. (Ed.), Patologia Clínica Veterinária. 3aㅡ ed. Guanabara Koogan, Rio de Janeiro.

Coles E.H. 1986b. Eritrócitos, p.72-121. In: Ibid. (Ed.), Patologia Clínica Veterinária. 3aㅡ ed. Guanabara Koogan, Rio de Janeiro.

Diefendenfer D.L. \& Brightling P. 1983. Dysuria due to urachal abscessation in calves diagnosed by contrast urography. Can. Vet. J. 24(7):218221.

Dyce K.M., Sack M.O. \& Weseing C.J.G. 2004. Sistema Cardiovascular, p.215255. In: Ibid. (Eds), Tratado de Anatomia Veterinária. $3^{a}$ ed. Elsevier, Rio de Janeiro.

Edwards III R.B. \& Fubini S.L. 1995. A one-stage marsupialization procedure for management of infected umbilical vein remnants in calves and foals. Vet. Surg. 24(1):32-35.

Fagliari J.J., Santana A.E., Lucas F.A., Campos Filho E. \& Curi P.R. 1998. Constituintes sanguíneos de bovinos recém-nascidos das raças Nelore (Bos indicus) e Holandesa (Bos taurus) e de bubalinos (Bubalus bubalis) da raça Murrah. Arq. Bras. Med. Vet. Zootec. 50(3):253-262.

Farin P.W., Piedrahita J.A. \& Farin C.E. 2006. Errors in development of fetus and placentas from in vitro-produced bovine embryos. Theriogenology 65(1):178-191.

Farin C.E., Farmer W.T. \& Farin P.W. 2010. Pregnancy recognition and abnormal offspring syndrome in catle. Reprod. Fertil. Dev. 22(1):75-87.

Figueirêdo L.J.C. 1999. Onfalopatias de bezerros. Editora da Universidade Federal da Bahia, Salvador. 94p.

Garry F.G., Adams R., Mccann J.P. \& Odde K.G. 1996. Postnatal characteristics of calves produced by nuclear transfer cloning. Theriogenology 45(1):141-152.

Gasparelli E.R.F., Camargo D.G., Yanaka R., Mendes L.C.N., Peiró J.R., Bovino F., Perri S.H.V. \& Feitosa F.L.F. 2009. Avaliação física e dos níveis séricos de cortizol de bezerros neonatos da raça Nelore, nascidos de partos normais e auxiliados. Pesq. Vet. Bras. 29(10):823-828.

Geishauser Th. \& Gründer H.D. 1992. Nabelentzündung beim Kalb: Ein Rückblick auf 104 Fälle. Tierärztl. Umschau 47(5):304-320.

Gloshal N.G. 1986, Coração e artérias, p.900-959. In: Getty R. (Ed.), Anatomia dos Animais Domésticos. 3aㅡ ed. Guanabara Koogan, Rio de Janeiro.

Habel R.E. 1986, Sistema digestório, p.807-858. In: Getty R. (Ed.), Anatomia dos Animais Domésticos. $3^{a}$ ed. Guanabara Koogan, Rio de Janeiro. 
Hasler J.F., Henderson W.B., Hurtgen P.J., Jin Z.Q., McCauley A.D., Mower S.A., Neely B., Shuey L.S., Stokes J.E. \& Trimmer S.A. 1995. Production, freezing and transfer of bovine IVF embryos and subsequent calving results. Theriogenology 43(1):141-152.

Hides S.J. \& Hannah M.C. 2005. Drying times of umbilical cords of dairy calves. Aust. Vet. J. 83(6):371-373.

Jacobsen H., Holm P., Schmidt M., Avery B., Greve T. \& Callesen H. 2003. No peri- and postnatal effects on calves born after transfer in vitro produced embryos vitrified by the open pulled straw (OPS) method. Acta Vet. Scand. 44(1/2):87-95.

Jacobsen H., Schmidt M., Holm P., Sangild P.T., Vajta G., Greve T. \& Callesen H. 2000. Body dimensions and birth and organ weights of calves derived from in vitro produced embryos cultured with or without serum and oviduct epithelium cells. Theriogenology 53(9):1761-1769.

Kaneko J.J. 1997. Serum proteins and Dysproteinemias, p.117-138. In: Kaneko J.J., Harvey J.W. \& Bruss M.L. (Eds), Clinical Biochemistry of Animals. $5^{\text {th }}$ ed. Academic Press, San Diego.

Kruip Th.A.M. \& den Daas J.H.G. 1997. In vitro produced and cloned embryos: Effects on pregnancy, parturition and offspring. Theriogenology 47:43-52.

Lischer C.J. \& Steiner A. 1993. Ultrasonography of umbilicus in calves. Part 1. Ultrasonographic description of umbilical involution in clinically heathy calves. Schweiz. Arch. Tierheilk. 135(8):221-230.

Lischer C.J. \& Steiner A. 1994. Ultrasonography of the umbilical structures in calves. Part 2: ultrasonography, diagnosis and treatment of umbilical diseases. Schweiz. Arch. Tierheilk. 136(6-7):227-241.

Madigan J.E. 2002. Diagnosis of umbilical disorders using ultrasound, p.285-288. In: Smith B.P.(Ed.), Large Animal Internal Medicine. $3^{\text {rd }}$ ed. Mosby, St Louis.

Meirelles F.V., Birgel Jr E.H., Perecin F., Bertolini M., Traldi A., Pimentel J.R.V., Komninou E.R., Sangalli J.R., Fantinato Neto P., Nunes M.T., Pogliani F.C., Meirelles F.D.P., Kubrusly F.S., Vannucchi C.I. \& Silva L.C.G. 2010. Delivery of cloned offspring: experience in Zebu cattle (Bos indicus). Reprod. Fertil. Dev. 22(1):88-97.

Miglino M.A., Pereira F.T.V., Visintin J.A., Garcia J.M., Meirelles F.V., Rumpf R., Ambrósio C.E., Papa P.C., Santos T.S., Carvalho A.F., Leiser R. \& Carter
A.M. 2007. Placentation in cloned cattle: structure and microvascular architecture. Theriogenology 68(4):604-617.

Noden D.M. \& Lahunta A. 2001. Sistema cardiovascular III: sistema venoso e linfático, p.281-290. In: Ibid. (Eds), Embriologia de los Animales Domesticos, Acribia S.A., Zaragoza.

Numabe T., Oikawa T., Kikuchi T. \& Horiuchi T. 2000. Birth weigth and birth rate of heavy calves conceived by transfer of in vitro or in vivo produced bovine embryos. Anim. Reprod. Sci. 64(1):13-20.

Nuss K. 2007. Erkrankungen der inneren Nabelstrukturen beim Rind. Tierärztl. Praxis 35(G):149-156.

O’Brien R.T. \& Forrest L.J. 1996. A retrospective study of umbilical sonography in calves. Vet. Radiol. Ultrasound 37(1):63-67.

Rérat M., Zbinden Y., Saner R., Hammon H. \& Blum J.W. 2005. In vitro embryo production: growth performance, feed efficiency, and hematological, metabolic, and endocrine status in calves. J. Dairy Sci. 88(7):25792593.

Rodrigues C.A., Santos P.S.P., Perri S.H.V., Teodoro P.H.M., Anhesini C.R., Araújo M.A. \& Filho M.N.V. 2010. Correlação entre os métodos de concepção, ocorrência e formas de tratamento das onfalopatias em bovinos: estudo retrospectivo. Pesq. Vet. Bras. 30(8):618-622.

Santos S.A., Silva R.A.M.S., Comastri Filho J.A., Abreu U.G.P., McManus C., Mariante A.S., Lara M.A.C., Pellegrin A.O. \& Ravaglia E. 2005. Desempenho de bezerros pantaneiros, Nelore e cruzados criados no Pantanal, Brasil. Arch. Zootec. 54(206/207):501-508.

Staller G.S., Tulleners E.P., Ree V.B. \& Spencer P.A. 1995. Concordance of ultrasonografic and phisycal findings in catle with mass or suspected to have infection of the umbilical cord remnants: 32 cases (1987-1989). J. Am. Vet. Med. Assoc. 206(1):77-81.

Trent A.M. \& Smith D.F. 1984. Surgical management of umbilical masses with associated umbilical cord remnant infections in calves. J. Am. Vet. Med. Assoc. 185(12):1531-1534.

Watson E., Mahaffey M.B., Crowell W., Selcer B.A., Morris D.D. \& Seginak L. 1994. Ultrasonography of the umbilical structures in clinically normal calves. Am. J. Vet. Res. 55(6):773-780.

Young L.E., Sinclair K.D. \& Wilmut I. 1998. Large offspring in catle and sheep. Rev. Reprod. 3(3):155-163. 